\title{
A case of low grade appendiceal mucinous neoplasm performed with laparoscopic ileocecal resection due to intussusception
}

\author{
Hiroaki Shidei $^{1)}$, Teppei Kono ${ }^{1,2)}$, Rie Imaizumi ${ }^{1)}$, Taro Koike ${ }^{1)}$, Hideyuki Yokokawa ${ }^{1,2)}$, \\ ${\text { Yoshitomo } \text { Ito }^{1)} \text {, Yutaka Miyano }}^{1)}$, Kunihiro Oyama ${ }^{1)}$, Shunichi Shiozawa ${ }^{2)}$, Kazuhiko Yoshimatsu ${ }^{1,2)}$ \\ ${ }^{1)}$ Department of Surgery, Saiseikai Kurihashi Hospital \\ ${ }^{2)}$ Department of Surgery, Tokyo Women's Medical University Medical Center East
}

\begin{abstract}
Low-grade appendiceal mucinous neoplasm (LAMN) is a rare disease. The strategy of treatment for LAMN has not been established. We herein present a case of LAMN treated by laparoscopic ileocecal resection with D2 lymph node (LN) dissection, which exhibited invagination. A 59-year-old man visited at our emergency room with intermittent abdominal pain. Abdomino-pelvic computed tomography $(\mathrm{CT})$ revealed suspiciously a diagnosis as intussusception of LAMN into the ascending colon. Emergency laparoscopic operation was performed. A laparoscopic ileocecal resection with D2 LN dissection was performed because swollen lymph nodes were notified around the ileocolic artery. Histologically, he was diagnosed as LAMN, T3, N0, M0, Stage II.
\end{abstract}

Keywords: Low-grade appendiceal mucinous neoplasm, Intussusception, Laparoscopic surgery

(Received June 8, 2020; Accepted July 1, 2020)

\section{Introduction}

The concept of low-grade appendiceal mucinous neoplasm (LAMN) is consistent with the recent edition of the World Health Organization (WHO) classification as one of appendiceal neoplasms, because of aggressive biological potential despite with a benign morphologic appearance ${ }^{1)}$. In Japan, it has been recognized as a tumor equivalent to borderline malignancy, however it has been newly classified in the 8th edition of Japanese Classification of Colorectal Carcinoma ${ }^{2}$. Little evidence is known in terms of treatment strategy for LAMN because of few reports of analyses using accumulated data $^{3)}$.

We herein report a case of LAMN underwent laparoscopic ileocecal resection with lymphadenectomy as an equivalent to cancer after diagnosis due to intussusception.

\section{Case report}

A 59-year-old man who had been aware of intermittent abdominal pain in 3 days visited at our emergency

Correspondence to: Kazuhiko Yoshimatsu, Department of Surgery, Saiseikai Kurihashi Hospital, 349-1105 Kouemon 714-6 Kuki city, Satama, Japan. Tel: +81480-52-3611, Fax: +81-480-52-0305, E-mail: kyoshsu@twmu.ac.jp room. He had no problems with his daily life. On arrival, his vital sign was stable. His physical findings showed that spontaneous pain and tenderness were obtained from the epigastric region to the right flank. No abnormal findings in his hematologic and chemical examination. Abdomino-pelvic computed tomography $(\mathrm{CT})$ revealed a $4 \mathrm{~cm}$-sized cystic tumor in the appendix with a uniform low density inverted into the ascending colon (Fig. 1). Emergency operation was scheduled under diagnosis as intussusception of suspiciously LAMN into the ascending colon. Under general anesthesia, laparoscopic operation was performed using 5 ports. Laparoscopic examination revealed that a certain swelling of the appendix was observed however intussusception had been already resolved (Fig. 2). There was no evidence of pseudo-myxoma. A laparoscopic ileocecal resection with D2 lymph node (LN) dissection was performed because swollen LNs were notified around the ileocolic artery. The macroscopic findings of the resected specimen showed that a swollen appendix had excluded the cecal wall (Fig. 3). Histopathologically, an atypical columnar epithelium with mucus grew papillary. A part of the epithelium fell off and was replaced by macrophages (Fig. 4a). The wall structure of the appendix collapsed due to a large amount of mucus accumulation, so that an accumulated mucus was in contact with the muscle layers of cecum (Fig. 4b). Finally, he was diagnosed as LAMN, T3, N0, M0, fStage II. Since his postoperative course was uneventful, he 

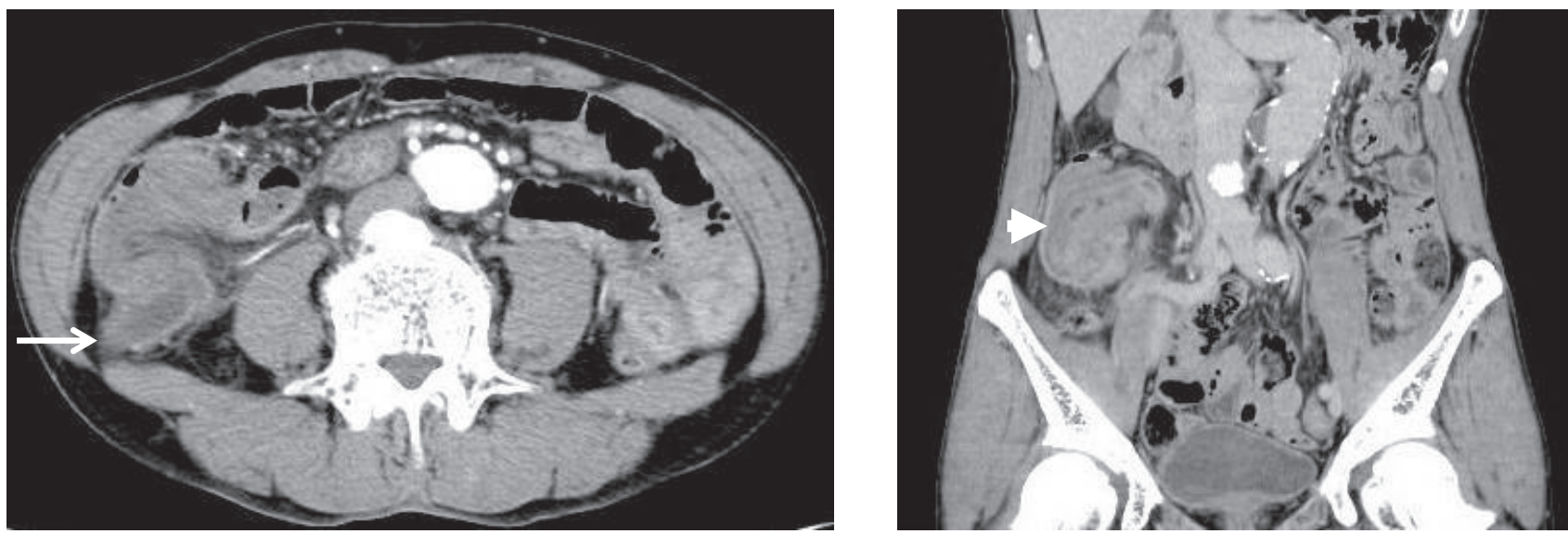

Fig. 1. CT scan revealed a $4 \mathrm{~cm}$-sized cystic tumor in the appendix with a uniform low density (white arrow). It inverted into the ascending colon (white arrow head).

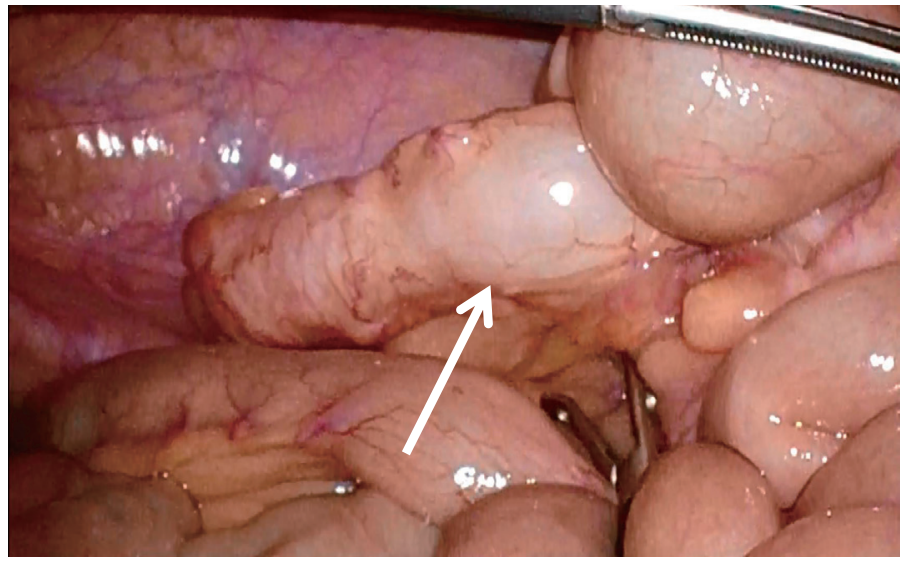

Fig. 2. Laparoscopic view revealed a marked swelling of the appendix was observed (white arrow) however intussusception had been already resolved.

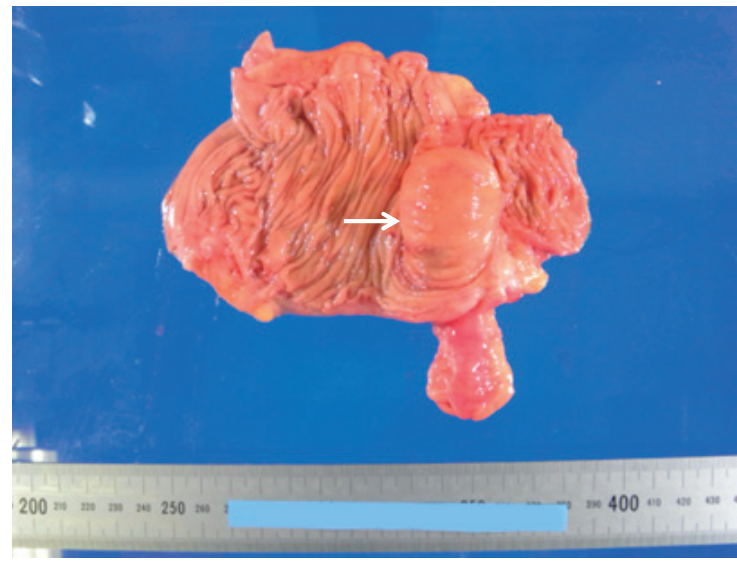

Fig. 3. A swollen appendix had excluded the cecal wall (white arrow) macroscopically.
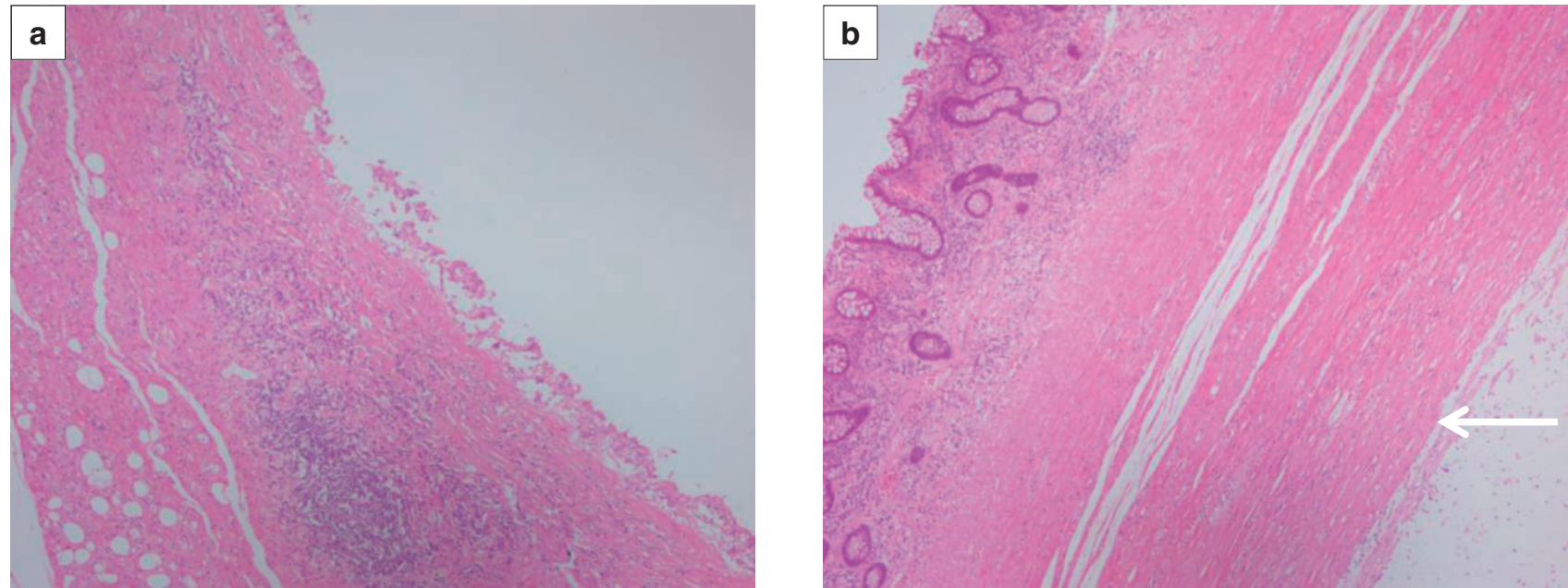

Fig. 4. A part of the epithelium fell off and was replaced by macrophages (a). An accumulated mucus was in contact with the muscle layers of cecum (white arrow: b).

discharged on postoperative day 8. Surveillance has been scheduled for Stage II colon cancer based on Japanese Society for Cancer of the Colon and Rectum (JSCCR) guidelines 2016 for the treatment of colorectal cancer. There is no symptom of relapse 15 months passed after surgery. 


\section{Discussion}

The appearance of LAMN is commonly an appendiceal mucocele, which is characterized by the large amount of mucin in the appendiceal lumen. In LAMN, acellular mucin only beyond muscularis propria rarely has a recurrence risk. However, the potential to develop a malignant condition is increased in patients with positive margin; appendiceal rupture; mucin, cells, or both outside the appendix; or pseudomyxoma peritonei ${ }^{5-8}$. Since cellular or acellular LAMN beyond muscularis propria should be already staged T3 category, careful attention should be needed in surgical procedure.

In this case, he was suspiciously diagnosed as LAMN with intussusception by the CT scan. Thereafter, an emergency operation was scheduled using laparoscopy. Under laparoscopic observation, he underwent laparoscopic ileocecal resection with D2 lymphadenectomy because of being observed an enlarged node belong to ileocolic vessels. Surgical resection is considered as the only curative treatment for LAMN. However, no definitive criterion for resection range is still unestablished. An appendectomy is enough for curative resection when the appendiceal root is intact ${ }^{9)}$. In the case of appendiceal mucinous adenocarcinoma, appendectomy could not be enough even when the appendiceal root is intact. The incidence of $\mathrm{LN}$ metastasis has been reported in $1.7 \%$ cases of $\mathrm{LAMN}^{10)}$; however, that of mutinous adenocarcinoma ranging from 25 to $50 \%{ }^{11)}$ and preoperative definitive diagnosis may be difficult ${ }^{12)}$. Therefore, ileocecal resection or right hemicolectomy with $\mathrm{LN}$ dissection is often performed. Analyses have been providing to clarify the clinicopathology of appendiceal cancer in a project study of the Japanese Society for Cancer of the Colon and Rectum. A treatment strategy will possibly be indicated based on their results.

\section{Conflict of interest:}

The authors declare that they have no conflict of interest.

\section{Reference}

1) Misdraji, J. (2015) Mucinous epithelial neoplasms of the appendix and pseudomyxoma peritonei. Mod Pathol. Suppl 1: S67-79. doi: 10.1038/modpathol.2014.129

2) Japanese Classification of Colorectal Carcinoma eighth edition. Japanese Society for Cancer of the Colon and Rectum. Kanehara \& Co., Ltd., Tokyo.

3) Xiao, J., Li, P., and Liu, W. (2020) Analysis of Clinical Characteristics of Low-Grade Appendiceal Mucinous Neoplasm (LAMN): A Retrospective Cohort Study of 51 LAMN Patients. J Invest Surg. Jan 6; 1-7. doi: 10.1080/08941939.2019.1695986 Online ahead of print.

4) Watanabe, T., Muro, K., Ajioka, Y., Hashiguchi, Y., Ito, Y., Saito, Y., Hamaguchi, T., Ishida, H., Ishiguro, M., Ishihara, S., Kanemitsu, Y. Kawano, H., Kinugasa, Y., Kokudo, N., Murofushi, K., Nakajima, T., Oka, S., Sakai, Y., Tsuji, A., Uehara, K., Ueno, H., Yamazaki, K., Yoshida, M., Yoshino, T., Boku, N., Fujimori, T., Itabashi, M., Koinuma, N., Morita, T., Nishimura, G., Sakata, Y., Shimada, Y., Takahashi, K., Tanaka, S., Tsuruta, O., Yamaguchi, T., Yamaguchi, N., Tanaka, T., Kotake, K., Sugihara, K,; Japanese Society for Cancer of the Colon and Rectum. (2016) Japanese Society for Cancer of the Colon and Rectum (JSCCR) guidelines 2016 for the treatment of colorectal cancer. Int J Clin Oncol. 23: 1-34. doi: 10.1007/s10147-017-1101-6

5) Li, X., Zhou, J., Dong, M., and Yang, L. (2018) Management and prognosis of lowgrade appendiceal mucinous neoplasms: a clinicopathologic analysis of 50 cases. Eur J Surg Oncol. 44: 1640-1645. doi: 10.1016/j.ejso.2018.06.037

6) Guaglio, M., Sinukumar, S., Kusamura, S., Milione, M. Pietrantonio, F., Battaglia, L., Guadagni, S., Baratti, D., and Deraco, M. (2018) Clinical surveillance after macroscopically complete surgery for Low-Grade Appendiceal Mucinous Neoplasms (LAMN) with or without limited peritoneal spread: long-term results in a prospective series. Ann Surg Oncol. 25: 878-884. doi: 10.1245/s10434-017-6305-5

7) Tiselius, C., Kindler, C., Shetye, J., Letocha, H., and Smedh, K. (2017) Computed tomography follow-up assessment of patients with low-grade appendiceal mucinous neoplasms: evaluation of risk for pseudomyxoma peritonei. Ann Surg Oncol. 24: 1778-1782. doi: 10.1245/s10434-016-5623-3

8) Arnason, T., Kamionek, M., Yang, M., Yantiss, RK., and Misdraji, J. (2015) Significance of proximal margin involvement in low-grade appendiceal mucinous neoplasms. Arch Pathol Lab Med. 139: 518-521. doi: 10.5858/arpa.2014-0246-OA

9) Ishikawa, H., Takamura, H., and Kuwata, H. A case report of mucinous cystadenocarcinoma of the appendix after appendectomy. (1986) Jpn J Gastroenterol Surg. 19: 67-70. doi: 10.5833/jjgs.19.67 In Japanese with English abstract.

10) Chua, TC., Moran, BJ., Sugarbaker, PH., Levine, EA., Glehen, O., Gilly, FN., Baratti, D., Deraco, M., Elias, D., Sardi, A., Liauw, W., Yan, TD., Barrios, P., Gómez Portilla, A., de Hingh, IH., Ceelen, WP., Pelz, JO., Piso, P., González-Moreno, S., Van Der Speeten, K., and Morris, DL. (2012) Early-and long-term outcome data of patients with pseudomyxoma peritonei from appendiceal origin treated by a strategy of cytoreductive surgery and hyperthermic intraperitoneal chemotherapy. J Clin Oncol. 30: 2449-2456. doi: 10.1200/JCO.2011.39.7166

11) McGory, ML., Maggard, MA., Kang, H., O’Connell, JB., and Ko, CY. (2005) Malignancies of the appendix: beyond case series reports. Dis Colon Rectum. 48: 2264-71. doi: 10.1007/s10350-0050196-4

12) Yamamoto, A., Shibutani, K., Inoue, M., Nakashima, K., Uchino, H., Sekiya, R., and Onitsuka, T. (2001) A Case of mucinous cystadenoma in appendix performed laparoscopic partial excision of cecum. Jpn Soc Gastroenterol Surg. 34: 1650-1654. doi: 10.5833/ jjgs.34.1650 In Japanese with English abstract. 